\title{
Adoption of Cropping Sequences in Northeast Montana: A Spatio-Temporal Analysis
}

John A. Long ${ }^{a}$, Rick L. Lawrence ${ }^{a}$, Perry R. Miller ${ }^{a}$, Lucy A. Marshall ${ }^{\text {b,a }}$, Mark C. Greenwood

${ }^{a}$ Department of Land Resources and Environmental Sciences

Montana State University

P.O. Box 173120

Bozeman, Montana, USA 59715-3120

${ }^{\mathrm{b}}$ School of Civil and Environmental Engineering

The University of New South Wales

Sydney NSW 2052, Australia

${ }^{\mathrm{c}}$ Department of Mathematical Sciences

Montana State University

P.O. Box 173120

Bozeman, Montana, USA 59715-3120

\section{Corresponding Author:}

John A. Long

Tel: 1-406-994-5073

john.long5@msu.montana.edu

(C) 2014. This manuscript version is made available under the Elsevier user license http://www.elsevier.com/open-access/userlicense/1.0/ 


\section{ABSTRACT}

Producers make the decision to adopt a particular agricultural practice within a range of social, economic, environmental, and agronomic constraints. The semiarid regions of the US northern Great Plains are dominated by dryland farming practices and the traditional practice has been to rotate small-grain cereals with summer fallow; however, producers are moving away from this practice. The area of fallow in northeastern Montana decreased by one-third and the area of pulse crops increased nearly six-fold during 2001-2012. We previously identified two key practices that are indicative of regionally changing agricultural practices: (1) the broad-scale adoption of cereal-pulse sequences, and (2) the conversion from continuous strip-cropping to block managed cereal-based sequences. Here, we examined the adoption of these two practices from a spatiotemporal perspective to determine if the observed patterns were consistent with those expected from a priori processes: random occurrence, spread and adoption of the practices due to social interaction as described in innovation diffusion theory, or adoption based on environmental factors. Our results suggest that the adoption and spread of both practices were likely constrained by the suitability of the physical environment. Available water, in particular, exerts a fundamental control on the decision whether or not to adopt either practice. We also found evidence for the expansion of these practices due, in part, to social factors, particularly during the early period of adoption. We conclude that producers made the decision whether or not to adopt these practices primarily as a function of environmental suitability and, to a lesser extent, within the context of social interactions.

\section{KEYWORDS}

Diffusion of innovation; Agriculture management practice; Spatio-temporal analysis; Cropping sequence 


\section{MANUSCRIPT}

\section{Introduction}

Innovations in technology and management practices are vital to the sustainability and increased productivity of agricultural systems; yet, the decisions to adopt them are made by individual farmers faced with incomplete information in terms of cost and price fluctuations, variability in weather conditions, and changes in agricultural policy (Schmit and Rounsevell, 2006). Crop rotation is a well-established 'innovative' practice with many benefits (see, e.g., Plourde et al., 2013), but farmers do not necessarily adhere to strict rotations (Long et al., 2014). The decision to grow crops in a specific sequence is made within environmental, socioeconomic, and agronomic constraints (Castellazzi et al., 2007).

Recent research (Long et al., 2014) identified several changes in the frequency of specific cropping sequences between 2001 and 2012 that are indicative of changing agricultural practices in northeast Montana. They concluded that regional producers: (1) increased the total amount of cropland in active production; (2) grew more cereal and reduced fallowed fields; (3) converted a substantial number of fields managed by strip-cropping to block management for cereal-based sequences; and (4) increased the prevalence of cereal-pulse sequences. Adoption of alternative cropping sequences, indicated by the last three findings, is innovative in that they represent new, and presumably more advantageous, practices. This previous work examined cropping sequences from a temporal perspective. Our research reported in this paper entailed the analysis of fieldlevel changes in cropping sequences in a spatio-temporal context by focusing on two of the key changes - the adoption of cereal-pulse sequences and the conversion from continuous stripcropping to block managed cereal-based sequences. Our goal was to determine if the observed spatio-temporal patterns of the changing practices were consistent with those expected from 
specific a priori processes: random occurrence, spread and adoption of the practices due to social interaction as described in innovation diffusion theory, or adoption based on environmental factors.

The mapped locations of objects or events can be analyzed as spatial point processes in which the geographical locations are the random element; the actual observed locations represent one of the many possible realizations of a random spatial point process. Spatial point pattern analysis is a common method to assess spatial heterogeneity and detect patterns (e.g., Liu et al., 2007). The primary purpose of spatial point pattern analysis is to determine if the observed locations exhibit some form of systematic patterning over an area and, if so, over what spatial scales does the patterning persist. Spatial point patterns that exhibit complete spatial randomness (CSR) are indicative of a purely stochastic process and imply the absence of causal behavior. Spatial point patterns that do not exhibit CSR possess structure, suggesting spatial dependency and the potential existence of an underlying process, such as a response to environmental heterogeneity (Perry et al., 2002).

CSR assumes that the locations follow a homogeneous Poisson process and have constant intensity over the area, whereas departures from CSR produce regularity or clustering. Regularity exists in patterns that are more evenly distributed (dispersed) than expected, while clustering indicates that the locations are closer together than expected from a purely random process (e.g., Diggle, 2003). These patterns have been identified in agricultural settings with a variety of established tests. Ripley's K-function has been used, for example, to detect clustering of agricultural areas affected by soil constraints (Dang et al., 2011) and in the yields from cacao stands (Ngo Bieng et al., 2013). 
The adoption and spread of farming practices has long been described by innovation diffusion theory. The diffusion of innovation, in its basic form, refers to the spread and adoption of an idea, technology, or behavior (e.g., Wejnert, 2002; Scholnick, 2012). Foundational work (Tarde, 1903) suggested that sociological imitation followed a characteristic S-shaped curve in which the rate of diffusion could be deduced from the slope of the ' $\mathrm{S}$ '. Steep slopes indicated a rapid rate of diffusion, while more gradual slopes were indicative of slower rates. The adoption of agricultural innovations, such as new machinery, seed varieties, or management practices, has provided the context for many advances in the theory. It was demonstrated, for example, that the abundance of technological improvements to the sulky plow, determined by the number of patents, followed an S-shaped curve (Chapin, 1928). An investigation of the diffusion of hybrid seed corn - innovative because the new seed substantially improved yields and produced plants with stronger stalks, making mechanical pickers more effective, showed that adoption by Iowa farmers followed an S-shaped curve with three distinct phases: (1) an initial adoption period characterized by slow growth; (2) a period in which the rate of adoption increased rapidly; and (3) a period of declining growth as the resistant farmers adopted the seed (Ryan and Gross, 1943; Ryan and Gross, 1950). Perhaps their most influential claim was that diffusion was a social process in which spread occurred from early to late adopters, rather than a process of decisions based on economics (Valente, 1995).

The Iowa study (Ryan and Gross, 1950) was framed in a predominantly temporal context and was geographically constrained, as it only considered diffusion in two specific farming regions in Iowa. An analysis of the adoption of various agricultural practices and the acceptance of government subsidies in Sweden more thoroughly considered the diffusion of innovations over space (Hägerstrand, 1953). This research concluded that the adoption of an innovation was 
a social process and spread outward from an initial cluster of adopters, with declining frequency of adoption as a function of distance and of physical barriers to communication, such as rivers or mountains (Hägerstrand, 1953; Johansen, 1971). Hägerstrand's model is, in many respects, similar to those used to describe the spread of a contagious disease (Clark, 1984). The model incorporates a set of six restrictive assumptions, primarily concerning the nature and means of communication, which diminishes its usefulness in modern applications. The Hägerstrand model, for example, assumes that face-to-face communication between farmers is the only mechanism by which knowledge of the innovation spreads (see, e.g., Hahvey, 1966 for a complete discussion). Later critics have re-analyzed Hägerstrand's data with more sophisticated statistical techniques, arguing that: (1) the initial cluster of adopters was not actually clustered (Cliff, 1968); (2) spatial autocorrelation was inadequately treated (Cliff and Ord, 1974); and (3) the model has little explanatory or predictive power if the socio-economic conditions are different from those experienced in Hägerstrand's study (Clark, 1984).

Models grounded in the idea of 'diffusion of innovation as a social process' persist in the literature, despite their shortcomings. The diminishing role of distance and physical barriers as a spatial constraint to the spread of information was recognized nearly 50 years ago (e.g., Hahvey, 1966). Furthermore, the social network of a twenty-first century farmer is unlikely to be wellcharacterized by the Euclidian distance between farms as assumed by Hägerstrand (Schmit and Rounsevell, 2006). Others (e.g., Beck, 1992) have argued that in a modern information society, traditional social networks are becoming less and less influential. The spread of information, and thus innovation, is no longer confined to a finite geographically-constrained social network of neighbors and colleagues, but includes all forms of modern communication and mass media. Information regarding agricultural innovations is available to all farmers in developed countries 
nearly simultaneously. Consequently, the strength of social interactions as a function of distance between farms is arguably a tenuous association at best. Research has demonstrated that fields cultivated by farmers in close proximity are statistically no more similar than fields cultivated by farmers who live further away from one another and has concluded that farmer imitation of their neighbors does not affect land use patterns directly (Schmit and Rounsevell, 2006).

Alternative viewpoints assert that the diffusion of an innovation over space is not strictly a function of social processes and include environmental context as a fundamental element. The adoption of an agricultural practice, in particular, depends on its suitability to the physical and economic environment (Wejnert, 2002). Management decisions are fundamentally subject to personal preferences, opinions, experiences, and the physical characteristics of the landscape. Observed differences in agricultural practices are inherently affected by spatial heterogeneity in physical characteristics (Rosenzweig et al., 2002; Rounsevell et al., 2003). Crop yields, for example, are linked to temperature and precipitation (e.g., Rosenzweig et al., 2002; Lobell et al., 2007). Annual precipitation varies and has a substantial effect on the decision to grow a specific crop. Many regional producers were unable to seed fields in 2011, for example, due to excessive precipitation; therefore, many fields were unintentionally fallowed. Precipitation is well-known to vary with northing (latitude), easting (longitude), and elevation. Consequently, northing, easting, elevation, and precipitation are geographic and environmental variables that might be correlated with the adoption of cropping sequences.

The purpose of this work was to investigate changes in specific cropping sequences in northeast Montana within a spatio-temporal context. We focused on the adoption of cereal-pulse sequences and the conversion from continuous strip-cropping to block managed cereal-based sequences. These changes are indicative of shifting agricultural practices and suggest that 
regional farmers are adopting these 'innovations', because they provide some advantage over the traditional practices. Specifically, we sought to answer the following questions: (1) were the locations of the adopted practices randomly distributed throughout the study area; (2) did the spatio-temporal patterns of adoption resembled those expected under innovation diffusion theory driven by social factors; and (3) were the spatio-temporal patterns of adoption associated with specific environmental factors.

\section{Material and Methods}

\subsection{Study area}

The study area is in northeastern Montana and includes Daniels, Sheridan, Roosevelt, and Valley Counties (Fig. 1). The region borders similar agricultural landscapes to the north and east, Saskatchewan and North Dakota respectively. Lake Fort Peck and the Missouri River form the southern boundary, while the western border consists largely of federal and state land. The region is characterized by low relief (Padbury et al., 2002) with the higher elevations in northern Valley County. Lower elevations are more common in the southeast portion of the study area, as well as along primary drainages such as the Missouri River, Poplar River, and Big Muddy Creek. The area has a semiarid climate with an average of $310 \mathrm{~mm}$ of annual precipitation, occurring primarily as rain between April and September (WRCC, 2011). Maximum temperatures in July average $31^{\circ} \mathrm{C}$, while January temperatures average $-10^{\circ} \mathrm{C}$ (WRCC, 2011). Shortgrass prairie and agriculture are the dominant land cover types. Dryland farming practices are dominant in the region (Tanaka et al., 2010), although center-pivot irrigation is not uncommon for producers in close proximity to the Missouri River. Agriculture consists largely of cereal crops, primarily spring wheat, and an increasingly substantial area of pulse crops; however, small amounts of other crops are grown within the Missouri River corridor (NASS, 2012; NASS, 2013). 


\subsection{Data}

We previously reported cropping sequences for 13,076 agricultural fields in the study area for 2001-2012, which were derived from Landsat imagery in conjunction with the Cropland Data Layer, cadastral data, ground reference data, and local producers' records (Long et al., 2014). Crops were identified by class: cereals (C), fallow (F), pulse crops (P), cereal-fallow stripcropping (S), or other $(\mathrm{O})$. Cereals included spring or winter wheat (Triticum aestivum L.), durum (Triticum turgidum L.), or barley (Hordeum vulgare L.); pulse crops included dry pea (Pisum sativum L.), lentil (Lens culinaris Medik.), or chickpea (Cicer arietinum L.). Fallow identified uncultivated agricultural land, while cereal-fallow strip-cropping referred to the regionally common practice of alternating 50 or $100 \mathrm{~m}$ wide strips of cereal and fallow within a field. Non-agricultural land and crops that were not cereals or pulses comprised the 'other' class. The temporal structure of the data was represented by a 12-character string (e.g., SCPCCPCCFCCC) for each of the 13,076 fields that described the classification of that particular field for each of the years 2001-2012.

These data were then used to identify 2-yr cropping sequences via a 2-yr moving window (2001-2002, 2002-2003, .., 2011-2012), and similarly structured windows to identify 3-yr sequences. A field with SCPCCPCCFCCC for its 12-yr sequence, for example, has eleven 2-yr sequences: SC, CP, PC, CC, CP, PC, CC, CF, FC, CC, and CC. This field also contains ten 3-yr sequences: SCP, CPC, PCC, CCP, CPC, PCC, CCF, CFC, FCC, and CCC. Here we focus only on the 2-yr sequences because the 3-yr sequences reached the same conclusions in our previous work (Long et al., 2014). We did not examine all 2-yr sequences - only those indicative of the two key changes in agricultural practices: (1) the increase in cereal-pulse sequences, and (2) the 
conversion from continuous strip-cropping to block managed cereal-based sequences. The sequences of interest, therefore, were $\mathrm{CP} / \mathrm{PC}$ and SC.

The geographic and environmental factors considered included: northing, easting, elevation, relative effective annual precipitation (REAP), and annual precipitation. These variables were extracted from existing, publicly available datasets. Spatial data consisted of UTM coordinates (northing and easting) for the centroid of each field. Field elevation was defined as the elevation at the field's centroid and was derived from the 1 arc-second $(\sim 30 \mathrm{~m})$ National Elevation Dataset (Gesch et al., 2002). Annual precipitation data came from the precipitation distribution model PRISM (Parameter-elevation Regressions on Independent Slopes Model), which uses point data in conjunction with a variety of datasets to produce spatiallygridded estimates of climatological variables (Daly, 2006; Daly et al., 2002, 1994). We used annual precipitation products (PRISM Climate Group, 2014) at a 4-km grid cell resolution to create eleven 2-yr means corresponding to the 2-yr cropping sequences, such that the 2001-2002 cropping sequence, for example, used the mean of the 2001 and 2002 PRISM data. REAP is a gridded (10-m) estimate of available moisture, accounting for precipitation, slope, aspect, and soil properties, based on a 30-yr period (NRCS, 2014). Each field, therefore, had a single REAP value over the study's time frame, unlike the PRISM data. REAP, therefore, better represents the general tendency over time with respect to water availability, compared to precipitation, which relates to water availability in a specific year. We used field centroids to determine the REAP as fields potentially could have more than one value.

\subsection{Analyses}

All analyses were performed in R, version 3.0.2 (R Core Team, 2013) and with the following packages: 'spatstat' (Baddeley and Turner, 2005), 'gmodels' (Warnes, 2013), 'HH' 
(Heiberger, 2014), 'MuMIn' (Barton, 2013), and 'effects' (Fox, 2003). Our first objective was to determine if the locations of fields using the adopted practices were randomly distributed within the study area. We assessed the spatial dependency among fields in each of the cropping sequences of interest by year to address this objective: (1) visually after applying a smoothing operation to show relative densities across the study area, and (2) quantitatively with point pattern analysis. The location of an agricultural field is not strictly a point, but an area. We used the centroid of each field as 'points' and justify this usage by noting that the centroids are pointlike at the scale in this study (e.g., Baddeley, 2008).

We used kernel density estimators (KDE) to map the density $f(s)$ for each cropping sequence and year in order to visually assess the spatial distributions. KDEs are common nonparametric density estimators that estimate the distribution of $f(s)$ from a finite set of points by smoothing. They are weighting functions that smooth the contribution of each observed data point over a local neighborhood such that the weights decrease with distance. The intensity function depends on kernel type and bandwidth; kernel type determines the shape of the weighting function and bandwidth determines the amount of smoothing (e.g., Waller and Gotway, 2004). The general consensus is that the choice of kernel is largely irrelevant, while the choice of bandwidth is crucial (e.g., Taylor, 1989). We experimented with a variety of kernels and found no discernible differences before settling on a Gaussian kernel. Intensity was, however, responsive to bandwidth. We chose bandwidths that maximized the point process likelihood cross-validation criterion (LCV) (see e.g., Loader, 1999 for a complete discussion). If $s_{1}, s_{2}, \ldots, s_{n}$ are locations in the study area, estimated intensity at a given point $s$ is given by

$$
f(s)=\frac{1}{n h} \sum_{i=1}^{n}\left(\frac{s-s_{i}}{h}\right)\left(\frac{1}{\sqrt{2 \pi}} e^{-\frac{\left(s-s_{i}\right)^{2}}{h^{2}}}\right)
$$


where $h$ is the bandwidth, $n$ is the number of locations, $s-s_{i}$ is the Euclidean distance between $s$ and $s_{i}$, and the last term on the right hand right is the two-dimensional Gaussian kernel (Cai et al., 2013).

Spatial randomness was assessed quantitatively with the L-function, a normalized version of Ripley's K-function (Besag, 1977; Ripley, 1977). The K-function evaluates the randomness of a point pattern across a spatial domain at a specified distance $r$, by comparing the expected number of points within a local neighborhood of radius $r$ of any point against the expected intensity $\lambda$, assuming CSR (Ripley, 1977). The discrete form of the K-function (e.g., Streib and Davis, 2011) is defined as

$$
\hat{K}(r)=\frac{1}{\lambda N} \sum_{i=1}^{N} \sum_{j=1, i \neq j}^{N} I_{r}\left(d_{i j}\right)
$$

where $d_{i j}$ is the Euclidean distance between locations $S_{i}$ and $s_{j}, \lambda$ is the intensity function (total number of points divided by area) and $I_{r}$ is an indicator function which takes the value of 1 if $d_{i j} \leq r$. Under CSR, the expected value of $K(r)$ is $\pi r^{2}$ and deviations from this value are indicative of clustering $\left(K(r)>\pi r^{2}\right)$ or dispersion $\left(K(r)<\pi r^{2}\right)$. The L-function is a normalization of the K-function that gives a more interpretable, linear expected value, and is defined as

$$
\hat{L}(r)=\sqrt{\hat{K}(r) / \pi} \text {. }
$$

The L-function assumes a homogeneous spatial process (stationary and isotropic) across the entire domain, which is problematic because this is unlikely in many applications (Gabriel and Diggle, 2009). Points near the border of the domain are also problematic because the local neighborhood of radius $r$ may lie partially outside of the domain. Consequently, we used the inhomogenous version of the L-function, a generalization applicable to non-stationary point 
processes (Baddeley et al., 2000), and border-corrected estimates for $K(r)$ to adjust for bias introduced by edge effects (see e.g., Ripley, 1979, 1977). We tested for departures from CSR by creating confidence envelopes for CSR based on Monte Carlo simulations $(n=500)$. We also used chi-squared tests of goodness-of-fit for point process models based on quadrat counts, which determines whether a point pattern is more clustered than would be expected by chance by comparing the observed number of cropping sequences in quadrats of a given size with the frequencies expected from a random process. If $O_{i}$ is the observed number of fields in the $i$ th quadrat, $E_{i}$ is the expected number of fields in the $i$ th quadrat under CSR, and $k$ is the total number quadrats, then the test statistic

$$
X^{2}=\sum_{i=1}^{k} \frac{\left(O_{i}-E_{i}\right)^{2}}{E_{i}}
$$

is asymptotically distributed as a chi-squared distribution with $k-2$ degrees of freedom under the null hypothesis of CSR.

Our second objective was to establish whether or not spatio-temporal patterns of adoption resembled those that would be expected under innovation diffusion theory driven by social factors. Spatial dependency among fields in each of the cropping sequences suggests the possible existence of an underlying process. If the spread of adoption for these cropping sequences was a social process that spread outward from an initial cluster of adopters, as suggested in much of the diffusion of innovation literature, then we would expect clustering around the original adopters, and more generally clustering in any year around adopters in the previous year. The restrictive assumptions of the Hägerstrand model and its variants were not met in our data; therefore, we abandoned this method. Instead, we tested for spatio-temporal clustering around the initial locations by considering a general contagion processes. A contagion process is a spatial point 
process in which the occurrence of an event raises the probability of observing subsequent events nearby (e.g., Waller and Gotway, 2004) - for example, if the locations of fields in a cropping sequence in the first year were geographically closer to fields in the same cropping sequence in the second year than they were to a randomly selected set of field locations from the second year.

For each field in a given cropping sequence at time $t_{n+1}$, we computed the Euclidean distance between it and the nearest field managed with the same cropping sequence at time $t_{n}$. From these values we found the average minimum distance, equivalent to the average nearest neighbor distance, between fields in the same cropping sequence during consecutive years. These were compared to the equivalent metric from Monte Carlo simulations $(n=100)$ of randomly selected fields. Let $A$ be the set of field centroids for a particular cropping sequence at time $t_{n}$ such that $A=\left\{a_{1}, a_{2}, \ldots, a_{i}\right\}$. Similarly, let $B=\left\{b_{1}, b_{2}, \ldots, b_{j}\right\}$ be the set of centroids for fields at time $t_{n+1}$ that are in the same cropping sequence as those in $A$, and let $C=\left\{c_{1}, c_{2}, \ldots, c_{j}\right\}$ be a set of $j$ randomly selected field centroids. We define $\mathbf{D}_{\text {min }}(\mathbf{a}, \mathbf{b})$ as the vector of minimum Euclidean distances between each element of $A$ and each element of $B$, while $\mathbf{D}_{\text {min }}(\mathbf{a}, \mathbf{c})$ is defined as the vector of minimum Euclidean distances between each element of $A$ and each element of $C$. A contagion process is suggested when

$$
\mathbf{D}_{\text {min }}(\mathbf{a}, \mathbf{b})<\mathbf{D}_{\text {min }}(\mathbf{a}, \mathbf{c})
$$

We fit a linear model for each cropping sequence with distances as the responses modeled as a function of time (years 2001-2002 / 2002-2003 through 2010-2011 / 2011-2012) and type (observed or random) and their interaction. Because of severe non-constant variance and skew in the residuals for this model, all analyses were performed on the log-distances, which alleviated 
concerns about violations of normality and constant variance assumptions. Contrasts were used to test for differences in the mean of the log-distances between types for each year.

Our final objective was to determine if the spatial patterns of cropping sequences were associated with certain environmental factors. We examined potential associations between cropping sequences and the environmental variables (easting, northing, elevation, REAP, and mean annual precipitation) with graphical explorations of the data. Then, we fit two suites of logistic regression models with cropping sequence as the binary response variable $(\mathrm{CP} / \mathrm{PC}$ or not $\mathrm{CP} / \mathrm{PC}$; SC or not SC). All possible models with the predictor variables and an easting-northing interaction were considered; the top-ranked models based on AICc (Akaike Information Criterion, corrected for finite sample size) are reported. Here, the log-odds of adopting the practice $(\mathrm{CP} / \mathrm{PC}$ or $\mathrm{SC})$ relative to a baseline of not adopting the practice were modeled as linear combinations of the environmental predictor variables for each cropping sequence. The baseline model gives the log-odds of a success,

$$
\log \left(\frac{\hat{\pi}}{1-\hat{\pi}}\right)=\beta_{0}+\beta_{1} X_{1}+\beta_{2} X_{2} \ldots+\beta_{K} X_{K}
$$

where $\hat{\pi}$ is the odds of adopting the practice, $1-\hat{\pi}$ is the odds of not adopting the practice, $\beta_{0}$ is

the model intercept, and $\beta_{1}, \ldots, \beta_{K}$ are the coefficients for the $X_{1}, \ldots, X_{K}$ predictor variables.

\section{Results}

\subsection{Point pattern analysis}

We used point pattern analysis to assess the spatial dependency among fields by cropping sequence and year to determine if the locations were randomly distributed throughout the study area. None of the cropping sequences were randomly distributed during any of the 2-yr periods. This was evident visually in the density maps (Figs. 2 and 3) and statistically from both the 
analysis of quadrat counts and the border-corrected inhomogeneous L-functions. Assessment of CSR based on quadrat counts consistently indicated clustering for both cropping sequences during 2001-2012 ( $p<0.01$ in all cases). These results were robust to quadrat size and clustering was indicated with quadrats as large as $25 \times 25 \mathrm{~km}$ and as small as $2.5 \times 2.5 \mathrm{~km}$. Assessment of CSR based on L-functions also indicated clustering for both sequences at similar ranges, typically 10-20 km (Table 1).

\subsection{Adoption of cropping sequences as a contagion process}

Spatio-temporal patterns of cropping sequence adoption driven by social factors suggests that fields in the adopted practice in a given year should be closer on average to locations that previously adopted the practice than would be expected from random locations. This was the case for CP/PC sequences from 2001-2004 (Fig. 4a); they were farther than expected, however, for the remainder of the study. There was strong evidence for different changes over time between the mean minimum log-distance between fields in $\mathrm{CP} / \mathrm{PC}$ cropping sequences and the mean minimum log-distance between fields under random field selection $(F(9,16820)=3.9, p<$ 0.0001). The main effects in the model with an interaction also showed strong evidence of differences (Type: $F(1,16820)=59.4, p<0.0001$; Time periods: $F(9,16820)=180.2, p<$ 0.0001). Pairwise contrasts, adjusted for multiple comparisons with a Bonferroni correction, showed strong evidence of differences between the observed and random fields in five of the ten time periods (Fig. 4a).

We also found that SC fields were closer on average to locations that previously adopted the practice than expected from random locations for all time periods except one (Fig. 4b). There was evidence of changes over time between the mean minimum log-distance between fields in SC sequences and the mean minimum log-distance between fields under random field selection 
$(F(9,4623)=2.15, p=0.0023)$. The main effects in the model with an interaction showed strong evidence of differences (Type: $F(1,4623)=10.48, p=0.0001$; Time periods: $F(9,4623)=7.27$, $p<0.0001)$. Bonferroni adjusted pairwise contrasts indicated that observed and random fields were significantly different in only one of the ten time periods (Fig. 4a).

\subsection{Adoption of cropping sequences as a function of the environment}

As an observational study, inferences are limited to the observations at hand,. The preliminary exploration of the data suggested that fields in $\mathrm{CP} / \mathrm{PC}$ sequences were potentially associated with locations that: (1) were farther north and east; (2) were at lower elevations; and (3) had higher REAP. The adoption of block-managed cereal-based sequences, in lieu of continuous strip-cropping, showed the same tendencies. The northing and easting trends are visually evident in the density plots (Figs. 2 and 3), particularly for the CP/PC sequences.

Logistic regression models were initially fit with all environmental variables and an interaction between easting and northing for each cropping sequence by time period; final models were selected based on AICc (Table 2). The logistic models were fit such that the baseline category was fields that had not adopted the cropping sequence; therefore, positive coefficients indicated variables that were associated with an increase in the likelihood that a field used the adopted practice and negative coefficients indicated variables that decreased the likelihood. We focused primarily on the direction of the association for the selected models, because we were more interested in identifying associations rather than predictive modeling.

The environmental variables that were associated with an increased likelihood that a field had adopted $\mathrm{CP} / \mathrm{PC}$ sequences varied temporally (Table 2). Positive coefficients for easting and northing in the first half of the study gave way to negative ones by 2007-2008. The coefficient of the easting-northing interaction was always opposite in sign from those of the main effects and 
therefore served to mediate the main effects. The effect of northing, because of the interaction, ranged from positive to negative depending on the easting value and the time frame; it was generally positive with the exception of the most western eastings from 2007-2008 onwards. The coefficients for elevation were negative early on, but changed to positive in 2005. Coefficients for precipitation and REAP were typically negative, when present in the final model, with few exceptions. This seemingly incongruous result is examined in the Discussion. When interpreting the coefficients in Table 2, we note that we used UTM coordinates for northing and easting; the units are in meters.

The environmental variables associated with an increased likelihood that a field had converted from strip-cropping to block management also varied temporally (Table 2). Northing and easting, when retained in the model, tended to be negative during 2001-2007 and positive afterwards. The easting-northing interaction was generally not retained prior to 2007, but had a negative sign in the succeeding years. Coefficients for elevation had mixed directions of estimated effects in the models, but they tended to be positive in the first half of the study. The coefficients for REAP and annual precipitation were typically negative, but were seldom selected in the final models.

\section{Discussion}

\subsection{Key indicators of changing agricultural practices}

Agricultural practices in northeast Montana are changing with respect to the management of cropping sequences. Two practices in particular have emerged as key indicators of changing agricultural practices in the region: (1) producers have adopted cereal-pulse sequences at a substantial rate - a six-fold increase within a decade; and (2) producers have simultaneously adopted block-managed cereal-based sequences in lieu of continuous strip-cropping such that the 
number of fields managed by continuous strip-cropping decreased four-fold (Long et al., 2014). Producers that converted from strip-cropping to cereal-based sequences adopted continuous cereal cropping sequences $49 \%$ of the time on average, block-managed cereal-fallow sequences $35 \%$ of the time, while cereal-pulse sequences were adopted $16 \%$ of the time (see Table 3 ). We examined the spatial distribution of the adoption of these practices to see if they were nonrandom and, if so, were they consistent with patterns expected from the spread and adoption of the practices due to social interaction or adoption based on environmental factors.

\subsection{The adoption of cereal-pulse cropping sequences}

The locations of fields that adopted cereal-pulse sequences were not randomly distributed at any time during the study, which suggests an underlying rationale for the adoption. All tests of spatial randomness indicated that these sequences were clustered on the landscape within a local neighborhood, typically $15-20 \mathrm{~km}$. This is visually evident in the density plots (Fig. 2), where we can distinguish regions with higher concentrations of $\mathrm{CP} / \mathrm{PC}$ sequences, particularly for the early portion of the study. We caution the reader that the density plots in Fig. 2 are not scaled equally, but are independently scaled with respect to the maximum probability for each year. Consequently, the colors do not reflect the same density across all plots and Fig. 2 cannot be used to compare maps from year to year.

We tested whether the observed patterns of adoption tended to cluster geographically around the fields that had originally adopted the practice. We defined 'original' to be those fields using the practice in 2001-2002, the first 2-yr sequence in our study. We see in Fig. 2 that the original adopters were in the eastern portion of the region, primarily in the vicinity of Medicine Lake. Clustering around the original adopters would suggest a contagion process - one in which the occurrence of a field in a $\mathrm{CP} / \mathrm{PC}$ sequence raises the probability of observing nearby fields in 
$\mathrm{CP} / \mathrm{PC}$ sequences in subsequent years. There was some evidence that the adoption of cerealpulse sequences in the region initially spread through a contagion process as fields in successive years were closer together than expected from a random process during 2001-2004, while the results for 2005-2012 indicated that successive CP/PC sequences were farther apart than would be expected from a random process. These differences were generally small in practical terms the statistical significance is largely a result of the substantial sample sizes. For example, the largest difference, between the 2008-2009 and the 2009-2010 sequences, indicated that the median for the observed distances was between 1.10 and 1.21 times the median for the random distances, or, equivalently, the median for the observed distances was 140-300 $\mathrm{m}$ farther than the median for random distances. The differences in all other time frames were smaller.

The observed spatial patterns of CP/PC adoption are not consistent with those expected given a strong contagion process. Collectively, we take the results to suggest that a weak contagion process might have operated during the early stages of cereal-pulse adoption, potentially driven by social processes, and within a radius of no more than $20 \mathrm{~km}$. Additional clusters formed during 2005-2012 at distances farther than the local clustering neighborhoods via nucleation (e.g., Yarranton and Morrison, 1974), and were not contagion processes.

Adoption of a cropping sequence depends on its suitability to the physical environment; therefore, we looked at the association between a suite of environmental variables and whether or not a field had adopted CP/PC cropping sequences. Modeling of the environmental variables (northing, easting, elevation, REAP, and annual precipitation) generally indicated that geography was strongly associated with the likelihood that a field had adopted CP/PC sequences. Soil type has the potential to be an important environmental variable in agricultural studies. We considered this early in the study, but all analyses indicated that soil type had no effect on whether or not a 
producer adopted either practice. The collective effect of easting, northing, and their interaction over time suggest that the adoption of $\mathrm{CP} / \mathrm{PC}$ sequences grew primarily in the northeastern portion of the study area between 2001 and 2007, and then expanded toward the southwest.

The models indicate that fields in $\mathrm{CP} / \mathrm{PC}$ sequences were initially associated with lower elevations, with the exception of the Missouri River corridor, but had begun to move upslope by 2005-2006. Some of the lowest elevations in the study area are in the vicinity of Medicine Lake - the location of the original clusters. The upslope expansion in the latter portion of the study was congruent with results from easting, as the terrain generally increases in elevation from east to west.

REAP was retained in the models only occasionally and, when present, had negative coefficients; precipitation was likewise negative. Thus, locations with higher REAP or precipitation were less likely to have adopted CP/PC sequences, after controlling for easting and northing effects in the models. These findings contradict the exploratory data analysis, which indicated that adoption of these sequences was associated with locations with high REAP and precipitation. REAP, by definition, does not vary over time and it has a conspicuous northeastsouthwest trend in the study area such that higher values are in the northeast. REAP also had a very strong positive relationship with easting ( $r=\sim 0.79$ depending on time frame) and a strong positive relationship with northing $(r=\sim 0.57)$. Similarly, annual precipitation had strong positive relationships with easting ( $r=0.39-0.89$ depending on time frame). This suggests that multi-collinearity was present in the predictor variables and that all interpretations must be made with caution because of this shared information.

The importance of the geographic variables requires interpretation, as geographic position does not inherently explain anything ecological, but functions as a surrogate for other 
environmental variables (e.g., Pereira and Fonseca, 2003). We conclude that the strong effect of geographic position is actually driven by water availability. This suggests that the adoption of the $\mathrm{CP} / \mathrm{PC}$ sequences began in locations with high REAP values, typically greater than $330 \mathrm{~mm}$, and gradually spread to locations with REAP values as low as $270 \mathrm{~mm}$. The same general pattern of spread from higher to lower water availability was true for annual precipitation. The environmental variables, collectively, implied that the adoption of $\mathrm{CP} / \mathrm{PC}$ sequences were initially located in the eastern portion of the study area and expanded, first to the northwest and then towards the southwest (see also Fig. 2). This relationship is consistent with a pattern in which adoption occurred in more favorable locations initially and expanded into marginal environments.

The more favorable locations for the adoption of $\mathrm{CP} / \mathrm{PC}$ sequences were those with greater levels of available water, i.e., locations with higher annual precipitation and higher REAP. We see this association with water play out as the original adopters were in locations with higher REAP (north and east) and expansion was progressively into locations with lower REAP. Fields using center-pivot irrigation to grow pulse crops were not common in the study region during 2001-2012; however, they were occasionally present in the west (Valley County) where REAP and annual precipitation were lowest. The evidence suggests that the adoption of CP/PC sequences possibly expanded via a contagion process during 2001-2003 and expansion via nucleation during 2004-2012, but this is inconclusive. A possible explanation is that the practice originally spread from the initial adopters to their neighbors, not all of whom continued with the practice; while producers farther away, initiated new clusters. Regardless of mechanism, expansion is likely related to the Farm Security and Rural Investment Act of 2002 (i.e., the 2002 
'Farm Bill'), which provided meaningful protection in the form of marketing loans and payments if market prices fall too low for producers of pulse crops (Hauser, 2002).

\subsection{The adoption of block-managed cereal-based sequences in lieu of strip-cropping}

Fields that abandoned continuous strip-cropping and adopted block-managed cerealbased sequences were, like the $\mathrm{CP} / \mathrm{PC}$ sequences, not randomly distributed at any time. Tests for spatial randomness indicated clustering within local neighborhoods of 5-17 km, approximately one-third smaller than the neighborhoods for the $\mathrm{CP} / \mathrm{PC}$ sequences. This is visually evident in the density plots (Fig. 3), where regions with higher concentrations of SC sequences are readily visible. We caution the reader again with respect to scaling in the density plots.

As before, we tested whether the observed patterns of adoption of block-managed cerealbased sequences tended to cluster around the fields that had adopted the practice. This was true for the majority of the study and there was evidence of differences in two of the ten comparisons (see Fig. 4b). We see in Fig. 3 that the original adopters were primarily located in two clusters: one near the center of the study region and another just north of Medicine Lake. The cluster north of Medicine Lake was coincident with an original cluster of CP/PC adoption. These data suggest that adoption of block-managed cereal-based sequences might have propagated as a contagion process; however, the distances between fields were not consistently significant. These distances were, as with the CP/PC sequences, small from a practical viewpoint - the largest corresponded to a 320-400 m difference between the observed and random distances on the original scale. We concluded that a weak socially-driven contagion and nucleation processes for the conversion from continuous strip-cropping to block-managed cereal-based sequences might have operated throughout the duration of the study. 
Modeling the environmental variables indicated that geographic position was associated with the likelihood that a field had adopted block-managed sequences in lieu of continuous strip cropping, but not as strongly nor as consistently as in the adoption of CP/PC sequences. Locations farther east and north were more likely to have adopted block-management. The northern and eastern locations were more likely to have adopted either continuous cropping of cereals or cereal-pulse sequences, while locations farther south and west favored the adoption of block-managed cereal-fallow sequences. Elevation generally indicated that the adoption of block-managed cereal-based sequences, like the adoption of CP/PC sequences, tended to move upslope - toward the west. REAP and annual precipitation were rarely retained in the models, but were strongly correlated with easting and northing as we found in the $\mathrm{CP} / \mathrm{PC}$ sequences. Therefore, we believe it is likely that, similar to the SC sequences, geographic position acted as a proxy for water. Together, the environmental variables suggest that adoption of block-managed cereal-based sequences initially occurred in the central and eastern portions of the study area and expanded first to the north and then toward the southwest (see also Fig. 3).

The principal driving factor for the adoption of block-managed cereal-based sequences, or alternatively the abandonment of continuous strip-cropping, during 2001-2012 was water. These conversions happened in locations with consistently higher levels of moisture, while the decision to continue managing fields via strip-cropping was confined to locations where the availability of water was less consistent. This pattern is logical given that strip-cropping entered widespread use in regions where rainfall is a limiting resource as a means to better manage soil water and to reduce losses due to Aeolian erosion. While environmental variables explained the locations of conversions, we cannot rule out the possibility that the decision to adopt blockmanagement or to continue strip-cropping also occurred within a social context. Adoption of 
block-management, in regions where it is feasible, seemed to happen more frequently than not amongst neighbors within $20 \mathrm{~km}$ of one another.

\section{Conclusion}

We investigated changes in two common cropping sequences in northeast Montana: (1) adoption of cereal-pulse cropping sequences; and (2) adoption of block managed cereal-based sequences in lieu of continuous strip-cropping. These sequences are key indicators of shifting agricultural practices in the region. Dryland farming has a history of developing and adopting management practices to capture and conserve rainfall, and to better manage soil moisture. Water efficiency is essential in the semiarid portions of the Northern Great Plains and, not surprisingly, water exerts a fundamental control on the decision whether or not to adopt either of these practices. Traditional cereal-fallow sequences are inefficient and producers in northeast Montana are moving away from strip-cropping, a form of cereal-fallow sequences, to blockmanagement of cereal-based sequences, including those with pulse crops in locations where the environment is suitable. It is possible that the expansion of these practices was due, in part, to social factors, particularly during the early periods of adoption. This suggests a process in which the 'neighbors' of the original adopters emulated nearby practices.

\section{ACKNOWLEDGEMENTS}

This manuscript is based upon work supported by the US Department of Energy and the National Energy Technology Laboratory under Award Number DE-FC26-05NT42587. It was prepared as an account of work sponsored by an agency of the United States Government. Neither the United States Government nor any agency thereof, nor any of their employees, makes any warranty, express or implied, or assumes any legal liability or responsibility for the accuracy, completeness, or usefulness of any information, apparatus, product, or process disclosed, or 
represents that its use would not infringe privately owned rights. Reference herein to any specific commercial product, process, or service by trade name, trademark, manufacturer, or otherwise does not necessarily constitute or imply its endorsement, recommendation, or favoring by the United States Government or any agency thereof. The views and opinions of authors expressed herein do not necessarily state or reflect those of the United States Government or any agency thereof.

\section{REFERENCES}

Baddeley, A. Turner, R., 2013. Spatstat (R package version 2.20.4). Available http://www.Rproject.org/.

Baddeley, A., 2008. Analysing spatial point patterns in R. Available http://www.csiro.au/Portals/Publications/Research--Reports/Spatial-Point-Patterns-inR.aspx.

Baddeley, A., Moller, J., Waagepetersen, R., 2000. Non- and semi-parametric estimation of interaction in inhomogeneous point patterns. Stat. Neerl. 54, 329-350.

Baddeley, A., Turner, R., 2005. spatstat: An R Package for Analyzing Spatial Point Patterns. J. Stat. Softw. 12, 1-42.

Barton, K., 2013. MuMIn: Multimodel Inference. (R package version 1.9.13). Available http://www.R-project.org/.

Beck, U., 1992. Risk Society: Towards a New Modernity. Sage, London.

Besag, J., 1977. Contribution to the discussion of Dr. Ripley’s paper. J. R. Stat. Soc. Ser. B 39, $193-195$.

Cai, X., Wu, Z., Cheng, J., 2013. Using kernel density estimation to assess the spatial pattern of road density and its impact on landscape fragmentation. Int. J. Geogr. Inf. Sci. 27, 222-230. 
Castellazzi, M.S., Perry, J.N., Colbach, N., Monod, H., Adamczyk, K., Viaud, V., Conrad, K.F., 2007. New measures and tests of temporal and spatial pattern of crops in agricultural landscapes. Agric. Ecosyst. Environ. 118, 339-349.

Chapin, F., 1928. Cultural Change. The Century Co., New York.

Clark, G., 1984. Innovation Diffusion: Contemporary Geographical Approaches. Geo Books, Norwhich, UK.

Cliff, A., 1968. The neighbourhood effect in the diffusion of innovations. Trans. Inst. Br. Geogr. $44,75-84$.

Cliff, A., Ord, K., 1974. Spatial autocorrelation. Pion, London.

Daly, C., 2006. Guidelines for assessing the suitability of spatial climate data sets. Int. J. Climatol. 26, 707-721.

Daly, C., Gibson, W., Taylor, G., Johnson, G., Pasteris, P., 2002. A knowledge-based approach to the statistical mapping of climate. Clim. Res. 22, 99-113.

Daly, C., Neilson, R., Phillips, D., 1994. A statistical-topographic model for mapping climatological precipitation over mountainous terrain. J. Appl. Meteorol. 33, 140-158.

Dang, Y.P., Pringle, M.J., Schmidt, M., Dalal, R.C., Apan, A., 2011. Identifying the spatial variability of soil constraints using multi-year remote sensing. F. Crop. Res. 123, 248-258.

Diggle, P., 2003. Statistical Analysis of Spatial Point Patterns. Oxford University Press, Oxford, UK.

Fox, J., 2013. Effects (R package version 3.0-3). Available http://www.R-project.org/.

Fox, J., 2013. Effect Displays in R for Generalised Linear Models. J. Stat. Softw. 8, 1-27.

Gabriel, E., Diggle, P.J., 2009. Second-order analysis of inhomogeneous spatio-temporal point process data. Stat. Neerl. 63, 43-51. 
Gesch, D., Oimoen, M., Greenlee, S., Nelson, C., Steuck, M., Tyler, D., 2002. The National Elevation Dataset. Photogramm. Eng. Remote Sensing 68, 5-11.

Hägerstrand, T., 1953. Innovation diffusion as a spatial process. The University of Chicago Press, Chicago.

Hahvey, D., 1966. Theoretical concepts and the analysis of Agricultural Land-use Patterns in Geography. Ann. Assoc. Am. ... 56, 361-374.

Hauser, B., 2002. Brief highlights of the 2002 Farm Bill. [WWW Document]. Available http://www.farmdoc.illinois.edu/policy/farmbill/policy_farmbill_2002.html.

Heiberger, R.M., 2014. HH (R package version 3.0-3). Available http://www.R-project.org/.

Johansen, H., 1971. Diffusion of strip cropping in southwestern Wisconsin. Ann. Assoc. Am. ... $13,671-684$.

Liu, D., Kelly, M., Gong, P., Guo, Q., 2007. Characterizing spatial-temporal tree mortality patterns associated with a new forest disease. For. Ecol. Manage. 253, 220-231.

Loader, C., 1999. Local Regression and Liklihood. Springer, New York.

Lobell, D.B., Cahill, K.N., Field, C.B., 2007. Historical effects of temperature and precipitation on California crop yields. Clim. Change 81, 187-203.

Long, J.A., Lawrence, R.L., Marshall L., \& Miller, P.R., 2014. Changes in field-level cropping sequences: Indicators of shifting agricultural practices. Agr. Ecosyst. Environ. 189, 1120.

NASS (National Agricultural Statistics Service), 2012. Montana agricultural statistics volume XLIX. United States Department of Agriculture, Washington, D.C.

NASS (National Agricultural Statistics Service), 2013. Data and statistics: Crops and plants.

[WWW Document]. URL http://www.nass.usda.gov/Statistics_by_Subject. 
Ngo Bieng, M.A., Gidoin, C., Avelino, J., Cilas, C., Deheuvels, O., Wery, J., 2013. Diversity and spatial clustering of shade trees affect cacao yield and pathogen pressure in Costa Rican agroforests. Basic Appl. Ecol. 14, 329-336.

Padbury, G., Waltman, S., Caprio, J., Coen, G., McGinn, S., Mortensen, D., Nielsen, G., Sinclair, R., 2002. Agroecosystems and land resources of the northern Great Plains. Agron. J. 94, $251-261$.

Pereira, P., Fonseca, M. Da, 2003. Nature vs. nurture: the making of the montado ecosystem. Conserv. Ecol. 7, 1-31.

Perry, J., Liebhold, A., Rosenberg, M., Dungan, J., Miriti, M., Jakomulska, A., Citron-Pousty, S., 2002. Illustrations and guidelines for selecting statistical methods for quantifying spatial pattern in ecological data. Ecography (Cop.). 25, 578-600.

Plourde, J.D., Pijanowski, B.C., Pekin, B.K., 2013. Evidence for increased monoculture cropping in the Central United States. Agric. Ecosyst. Environ. 165, 50-59.

R Development Core Team, 2011. R: A Language and Environment for Statistical Computing (version 2.13.1). Available http://www.R-project.org/.

Ripley, B., 1977. Modelling spatial patterns. J. R. Stat. Soc. Ser. B 39, 172-192.

Ripley, B., 1979. Tests of "randomness" for spatial point patterns. J. R. Stat. Soc. Ser. B 41, $368-374$.

Rosenzweig, C., Tubiello, F.N., Goldberg, R., Mills, E., Bloomfield, J., 2002. Increased crop damage in the US from excess precipitation under climate change. Glob. Environ. Chang. $12,197-202$. 
Rounsevell, M.D.., Annetts, J.., Audsley, E., Mayr, T., Reginster, I., 2003. Modelling the spatial distribution of agricultural land use at the regional scale. Agric. Ecosyst. Environ. 95, 465479.

Ryan, B., Gross, N., 1943. The diffusion of hybrid seed corn in two Iowa communities. Rural Sociol. 8, 15-24.

Ryan, B., Gross, N., 1950. Acceptance and diffusion of hybrid corn seed in two Iowa communities. Res. Bull. 372, Iowa Agric. Exp. Stn. 663-708.

Schmit, C., Rounsevell, M.D., 2006. Are agricultural land use patterns influenced by farmer imitation? Agric. Ecosyst. Environ. 115, 113-127.

Scholnick, J.B., 2012. the Spatial and Temporal Diffusion of Stylistic Innovations in Material Culture. Adv. Complex Syst. 15, 1150010-1 - 1150010-18.

Streib, K., Davis, J.W., 2011. Using Ripley’s K-function to improve graph-based clustering techniques, in: IEEE Conference on Computer Vision and Pattern Recognition 2011. IEEE, Colorado Springs, pp. 2305-2312.

Tanaka, D., Lyon, D., Miller, P., Merrill, S., McConkey, B., 2010. Soil and Water Conservation Advances in the Semiarid Northern Great Plains, in: Zobeck, T., Schillinger, W. (Eds.), Soil and Water Conservation in the United States (SSSA Special Publication 60). Madison, WI, pp. $81-102$.

Tarde, G., 1903. The Laws of Imitation. Henry Holt and Company, New York.

Taylor, C., 1989. Bootstrap choice of the smoothing parameter in kernel density estimation. Biometrika 76, 705-712.

Valente, T., 1995. Network models of the diffusion of innovations. Hampton Press, New York. 
Waller, L., Gotway, C., 2004. Applied Spatial Statistics for Public Health Data. John Wiley \& Sons, Inc., Hoboken, NJ.

Warnes, G.R., 2013. Gmodels (R package version 2.14.4.1). Available http://www.Rproject.org/.

Wejnert, B., 2002. Integrating Models of Diffusion: A Conceptual Framework. Annu. Rev. Sociol. 28, 297-326.

WRCC, 2011. Local Climate Summary for Glasgow, Montana [WWW Document]. URL http://www.wrcc.dri.edu/summary/ggw.mt.html. (accessed 7.11.13).

Yarranton, A.G.A., Morrison, R.G., 1974. Spatial Dynamics of a Primary Succession $\square$ : Nuceation. J. Ecol. 62, 417-428. 
Table 1

2 Maximum Clustering Range by Cropping Sequence and Time Period ${ }^{\text {a }}$

\begin{tabular}{crrrrrrrrrrr}
\hline & & \multicolumn{1}{c}{ Time Period } \\
Sequence & $2001-02$ & $2002-03$ & $2003-04$ & $2004-05$ & $2005-06$ & $2006-07$ & $2007-08$ & $2008-09$ & $2009-10$ & $2010-11$ & $2011-12$ \\
\hline CP/PC & 3.0 & 18.5 & 20.6 & 20.5 & 25.5 & 14.7 & 15.4 & 15.8 & 14.9 & 17.4 & 16.8 \\
SC & 11.9 & 9.8 & 10.3 & 16.8 & 11.3 & 12.5 & 16.1 & 12.0 & 17.1 & 5.0 & 5.2
\end{tabular}

$3{ }^{a}$ Approximate maximum range $(\mathrm{km})$ for clustering based on the $95 \%$ confidence envelope from a border-corrected inhomogeneous L-

4 Function. $\mathrm{CP} / \mathrm{PC}=$ cereal-pulse, $\mathrm{SC}=$ conversion from strip-cropping to cereal-based sequences. 
7 Coefficients for the Top-ranked Logistic Regression Models ${ }^{\text {a }}$

\begin{tabular}{|c|c|c|c|c|c|c|c|c|c|}
\hline Sequence & Time Period & $d f$ & $n$ & Easting & Northing & Easting:Northing & Elevation & REAP & Precipitation \\
\hline \multirow[t]{11}{*}{$\mathrm{CP} / \mathrm{PC}$} & $2001-2002$ & 5 & 6338 & $7.05 e-04$ & $6.41 \mathrm{e}-05$ & $-1.29 \mathrm{e}-10$ & $-4.24 \mathrm{e}-03$ & --- & --- \\
\hline & 2002-2003 & 4 & 6445 & $7.64 \mathrm{e}-04$ & $7.53 e-05$ & $-1.39 e-10$ & --- & --- & --- \\
\hline & 2003-2004 & 7 & 6097 & $7.94 e-04$ & 7.99e-05 & $-1.46 e-10$ & $-3.93 e-03$ & $-7.60 e-02$ & $-1.79 \mathrm{e}-02$ \\
\hline & 2004-2005 & 6 & 5681 & $5.51 \mathrm{e}-04$ & $5.72 \mathrm{e}-05$ & $-1.01 e-10$ & --- & $-5.78 e-02$ & $-1.09 \mathrm{e}-02$ \\
\hline & 2005-2006 & 6 & 5763 & $5.43 e-04$ & $5.93 e-05$ & $-9.61 \mathrm{e}-11$ & $4.50 \mathrm{e}-03$ & --- & $-6.44 e-03$ \\
\hline & 2006-2007 & 6 & 6044 & $2.95 \mathrm{e}-04$ & $3.76 \mathrm{e}-05$ & $-5.02 \mathrm{e}-11$ & $3.19 \mathrm{e}-03$ & --- & $-8.23 e-03$ \\
\hline & 2007-2008 & 7 & 7037 & $-8.34 \mathrm{e}-04$ & $-6.00 e-05$ & $1.57 \mathrm{e}-10$ & 4.87e-03 & $-1.56 e-01$ & 8.60e-03 \\
\hline & 2008-2009 & 7 & 7509 & $-1.33 e-03$ & $-1.05 e-04$ & $2.49 \mathrm{e}-10$ & 4.95e-03 & $-1.13 e-01$ & $-4.77 e-03$ \\
\hline & 2009-2010 & 6 & 7659 & $-1.41 e-03$ & $-1.13 e-04$ & $2.65 \mathrm{e}-10$ & $3.41 \mathrm{e}-03$ & -- & $-1.26 \mathrm{e}-02$ \\
\hline & 2010-2011 & 6 & 7516 & $-1.52 \mathrm{e}-03$ & $-1.19 e-04$ & $2.85 e-10$ & $3.27 e-03$ & --- & $-1.58 e-02$ \\
\hline & 2011-2012 & 6 & 7542 & $-1.07 e-03$ & $-8.12 e-05$ & 2.01e-10 & $2.36 \mathrm{e}-03$ & $-6.64 e-02$ & --- \\
\hline \multirow[t]{11}{*}{$\mathrm{SC}$} & $2001-2002$ & 6 & 6338 & $-8.28 \mathrm{e}-04$ & $-8.49 \mathrm{e}-05$ & $1.55 \mathrm{e}-10$ & $7.40 \mathrm{e}-03$ & --- & $-2.29 \mathrm{e}-02$ \\
\hline & $2002-2003$ & 4 & 6445 & $3.58 \mathrm{e}-06$ & --- & --- & $3.19 \mathrm{e}-03$ & --- & $-1.92 \mathrm{e}-02$ \\
\hline & 2003-2004 & 3 & 6097 & -- & $-7.19 \mathrm{e}-06$ & --- & $1.65 \mathrm{e}-03$ & --- & --- \\
\hline & 2004-2005 & 3 & 5681 & --- & --- & --- & $1.43 \mathrm{e}-03$ & --- & $8.71 \mathrm{e}-03$ \\
\hline & 2005-2006 & 3 & 5763 & $-2.46 e-06$ & --- & --- & $3.33 \mathrm{e}-03$ & --- & --- \\
\hline & 2006-2007 & 4 & 6044 & $-7.04 \mathrm{e}-06$ & $-6.36 e-06$ & --- & $1.50 \mathrm{e}-03$ & --- & --- \\
\hline & 2007-2008 & 5 & 7037 & $5.81 \mathrm{e}-04$ & $5.19 \mathrm{e}-05$ & $-1.09 e-10$ & $-2.94 \mathrm{e}-03$ & --- & --- \\
\hline & 2008-2009 & 5 & 7509 & $1.27 e-03$ & $1.14 \mathrm{e}-04$ & $-2.37 e-10$ & $-5.01 e-03$ & --- & --- \\
\hline & 2009-2010 & 6 & 7659 & $9.48 e-04$ & $9.15 e-05$ & $-1.76 e-10$ & --- & $-2.20 \mathrm{e}-01$ & $1.26 \mathrm{e}-02$ \\
\hline & 2010-2011 & 5 & 7516 & $1.09 \mathrm{e}-03$ & $9.52 \mathrm{e}-05$ & $-2.01 e-10$ & --- & $-2.03 e-01$ & --- \\
\hline & 2011-2012 & 4 & 7542 & $8.62 \mathrm{e}-04$ & $6.86 \mathrm{e}-05$ & $-1.61 e-10$ & --- & --- & --- \\
\hline
\end{tabular}

8

$9{ }^{a}$ Coefficients for the top-ranked logistic regression models by sequence and time period. Coefficients with $p$-values $<0.05$ are in

10 bold; $d f=$ degrees of freedom, $n=$ sample size. 


\section{Table 3}

13 Conversions from Continuous Strip-Cropping to Cereal-Based Sequences as a Percentage of All Conversions ${ }^{\text {a }}$

\begin{tabular}{crrrrrrrrrr}
\hline & & \multicolumn{9}{c}{ Time Period } \\
& $2001-03$ & $2002-04$ & $2003-05$ & $2004-06$ & $2005-07$ & $2006-08$ & $2007-09$ & $2008-10$ & $2009-11$ & $2010-12$ \\
\hline SCC & 65.4 & 72.2 & 35.4 & 31.1 & 36.4 & 55.7 & 60.0 & 54.1 & 50.0 & 28.3 \\
SCF/SFC & 25.3 & 23.1 & 45.1 & 32.9 & 36.7 & 29.3 & 27.7 & 32.9 & 36.4 & 57.1 \\
SCP/SPC & 9.3 & 4.7 & 19.5 & 36.0 & 26.9 & 15.0 & 12.3 & 13.0 & 13.6 & 14.6
\end{tabular}

$14{ }^{a}$ The percentage of conversions from strip-cropping to cereal-based rotations by the type of rotation. SCC = conversion to continuous

15 cereal, $\mathrm{SCF} / \mathrm{SFC}=$ conversion to cereal-fallow, SCP/SPC $=$ conversion to cereal-pulse. 


\section{FIGURE CAPTIONS}

18 Fig. 1. The study area in northeastern Montana included the counties of Daniels, Roosevelt,

19 Sheridan and Valley. The agricultural regions are green.

20 Fig. 2. Kernel density maps for the locations of fields that had adopted CP/PC sequences by

21 year. Note that the probability scale next to each map is scaled independently for each year and

22 cannot be used to compare maps from year to year.

23 Fig. 3. Kernel density maps for the locations of fields that had adopted block-managed cereal-

24 based sequences in lieu of continuous strip-cropping by year. Note that the probability scale next

25 to each map is scaled independently for each year and cannot be used to compare maps from

26 year to year.

27 Fig. 4. Plots of the mean minimum log-distance between fields (+/- 1 SE) in (a) CP/PC

28 sequences and (b) SC sequences, and the mean minimum log-distance between fields under

29 random field selection. Blue lines are between observed sequences and pink lines are between

30 observed and random selection. Time periods with asterisks indicate time periods where the

31 difference in mean log-distances between "Type" is detectably different (Bonferroni corrected $p$ -

32 values $<0.05)$. Time periods represent the comparison of two 2-yr sequences: T0 = 2001-2002 /

33 2002-2003; T1 = 2002-2003 / 2003-2004; T2 = 2003-2004 / 2004-2005; T3 = 2004-2005 /

34 2005-2006; T4 = 2005-2006 / 2006-2007; T5 = 2006-2007 / 2007-2008; T6 = 2007-2008 /

35 2008-2009; T7 = 2008-2009 / 2009-2010; T8 = 2009-2010 / 2010-2011; T9 = 2010-2011 /

$36 \quad 2011-2012$. 


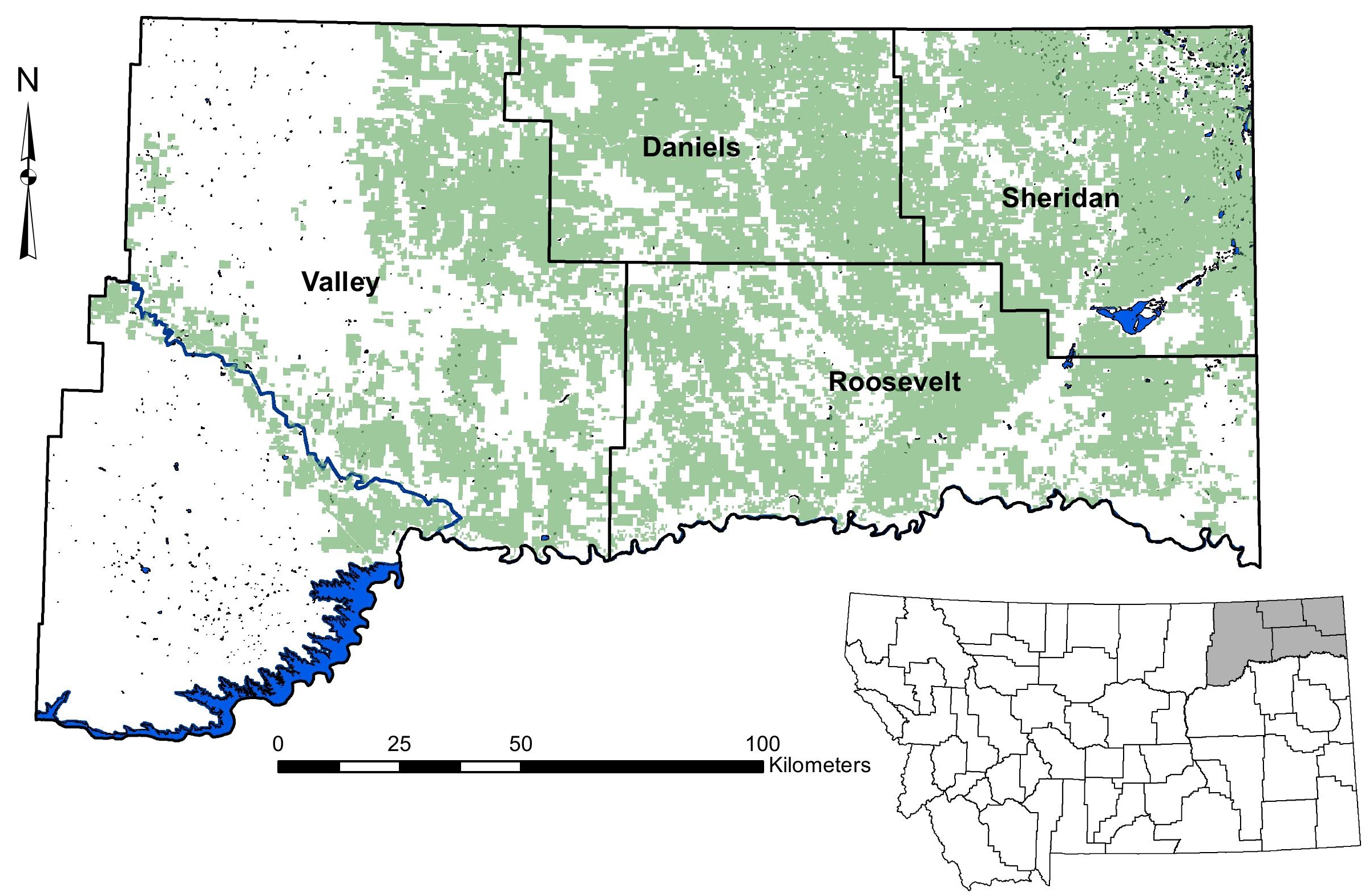




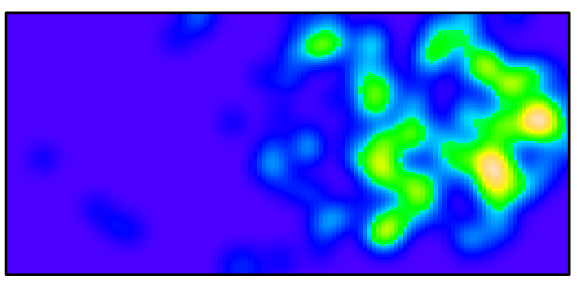

2004-2005

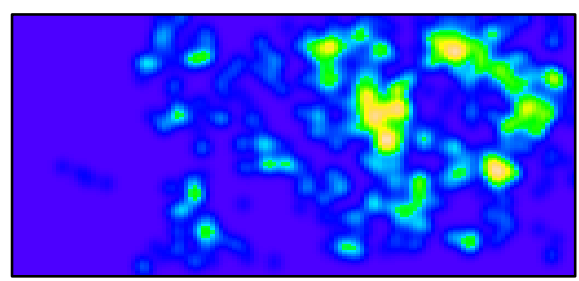

2007-2008
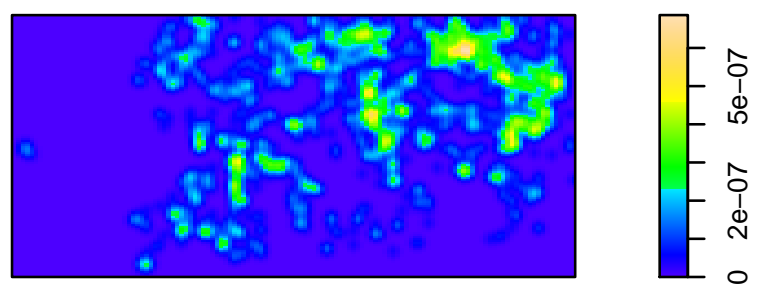

2010-2011
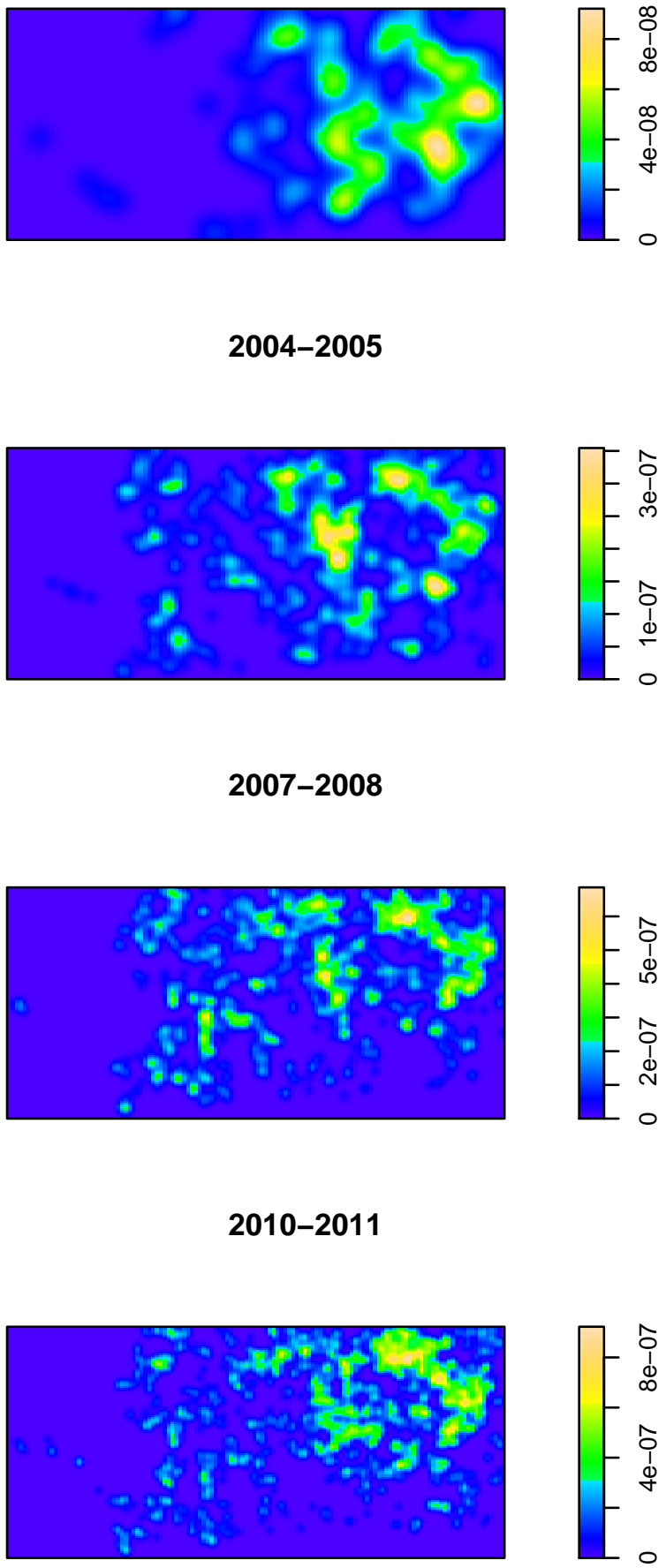

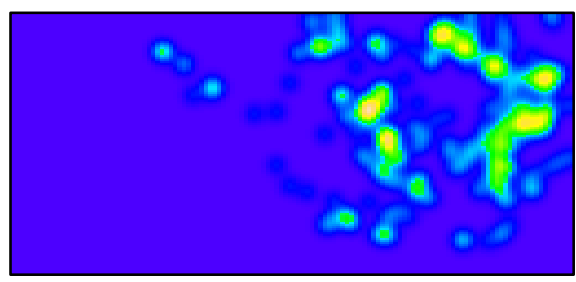

2005-2006

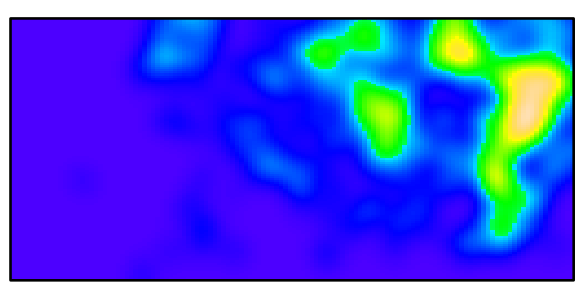

2008-2009
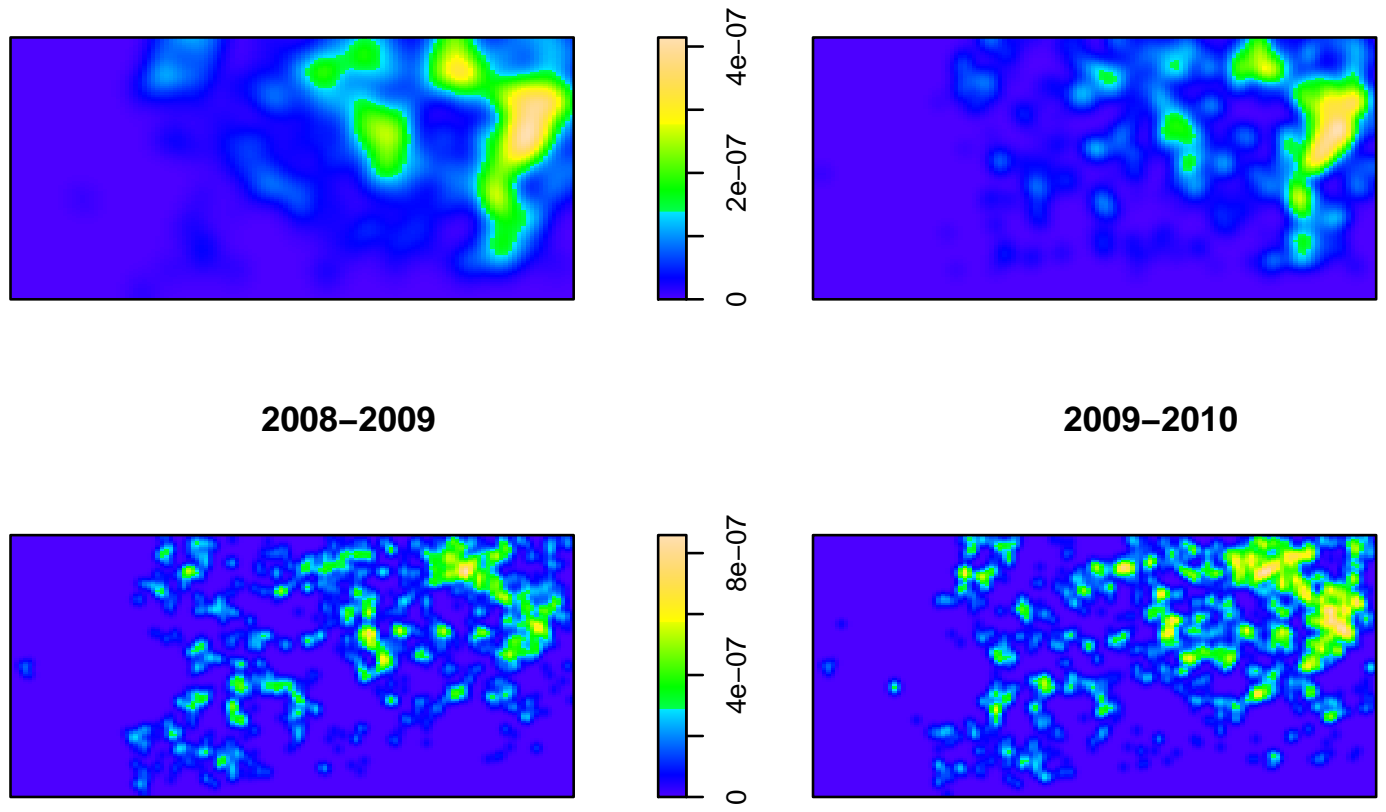

2011-2012

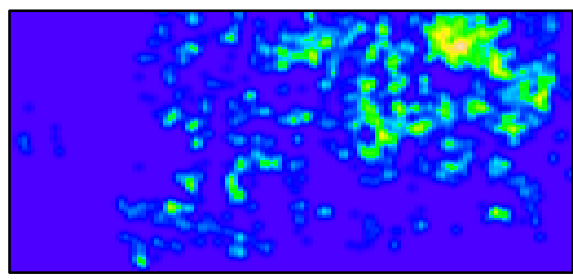

2009-2010

$\left[\begin{array}{l}\hat{0} \\ 1 \\ 0 \\ 0 \\ 0 \\ - \\ 0 \\ 0 \\ 0 \\ 1 \\ 0 \\ 0 \\ 0\end{array}\right.$

2006-2007

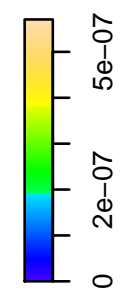

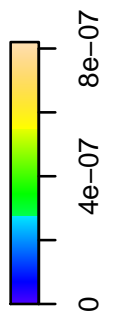




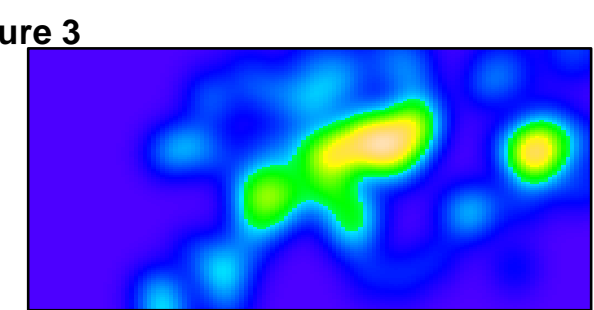

2004-2005

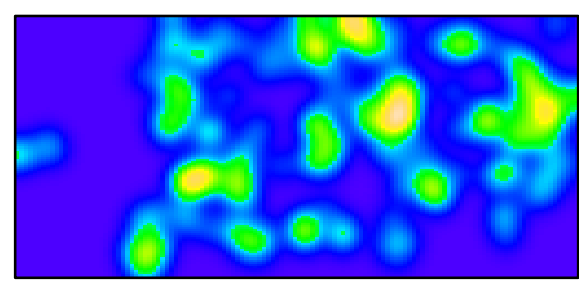

2007-2008

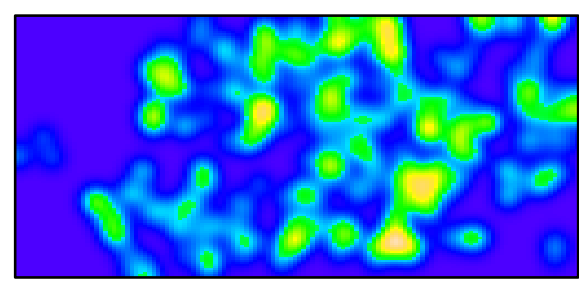

2010-2011

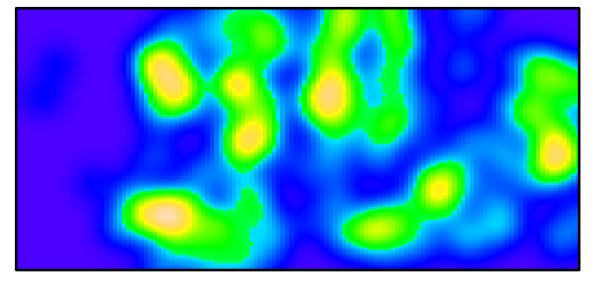

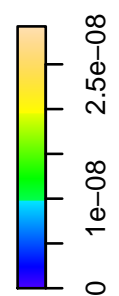

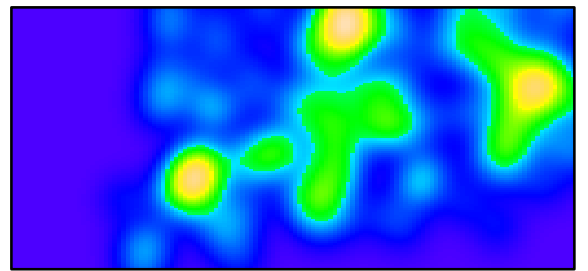

2005-2006
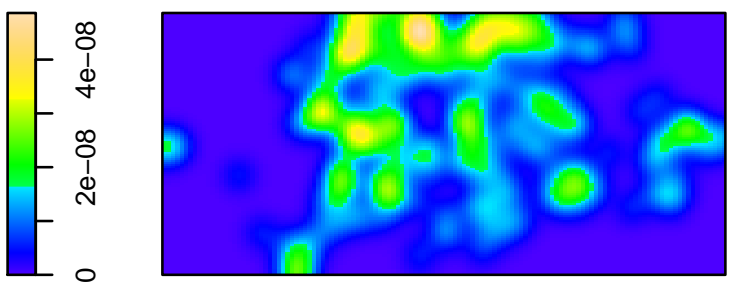

2008-2009
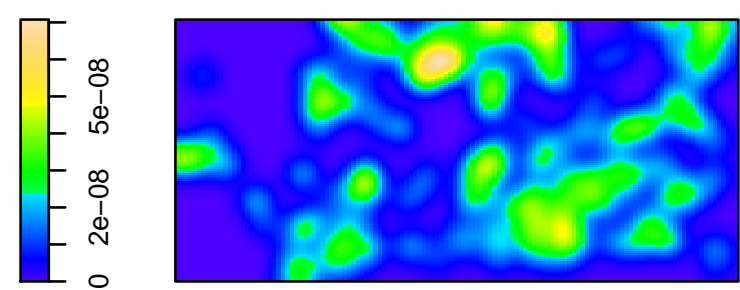

2011-2012
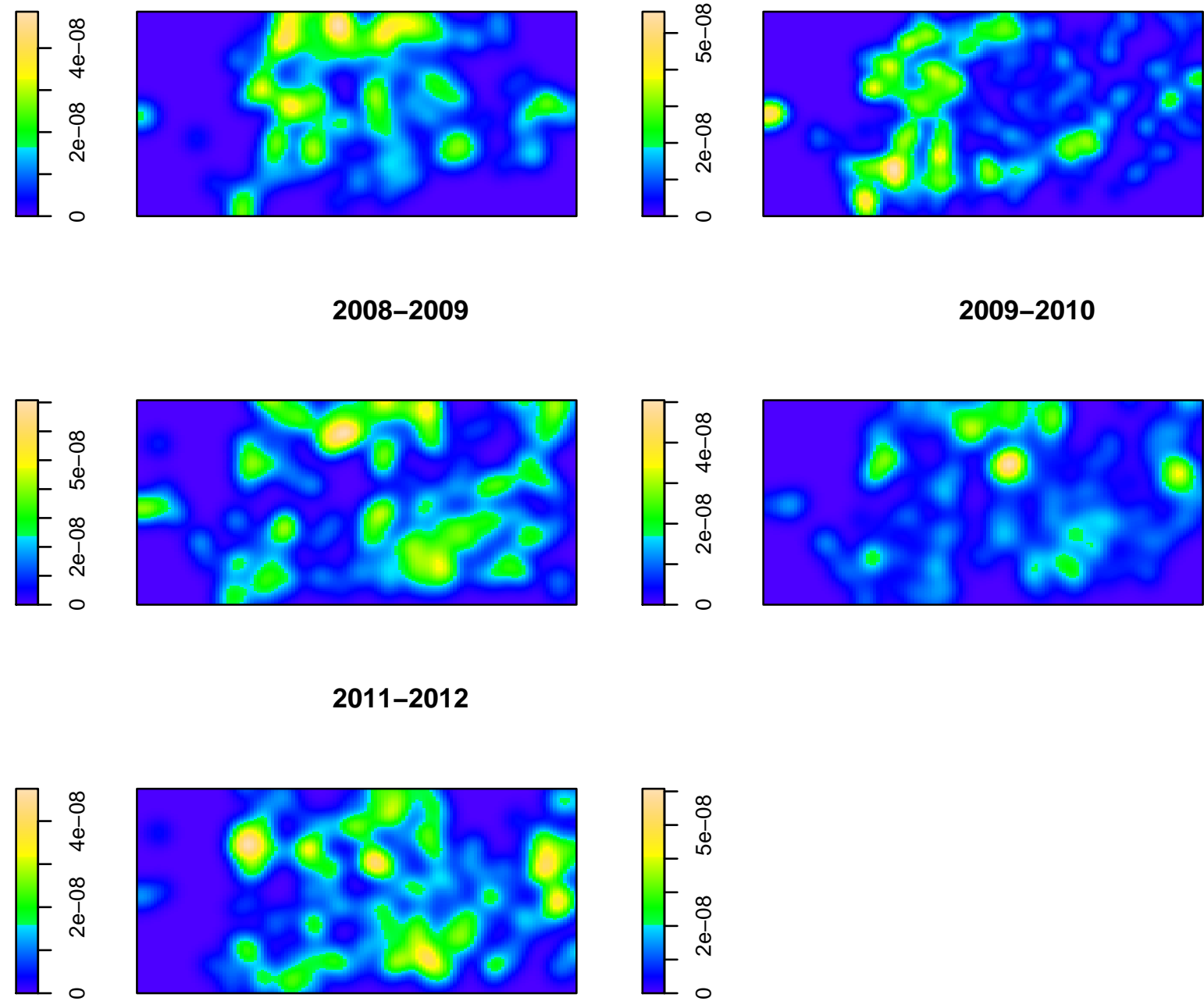

$\left[\begin{array}{l}\infty \\ 0 \\ 0 \\ 0 \\ 0 \\ -1 \\ -\infty \\ 0 \\ 0 \\ 0 \\ 0 \\ 0\end{array}\right.$
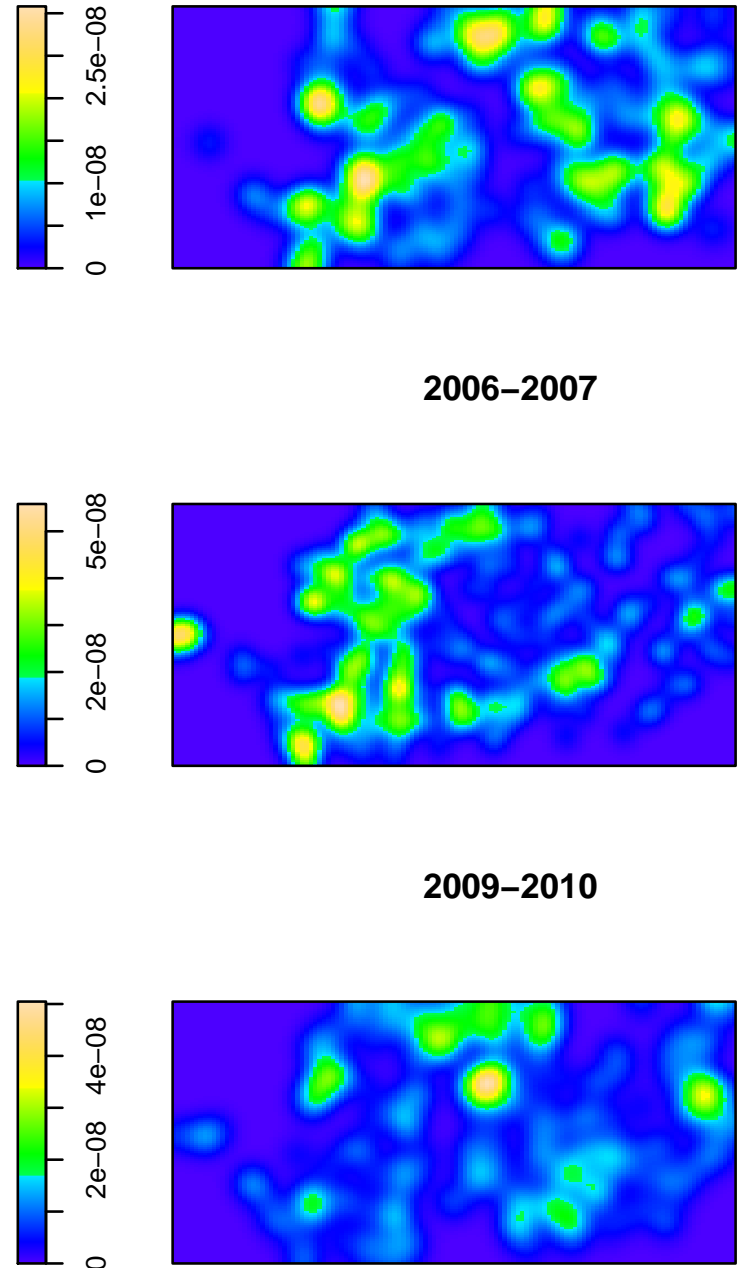

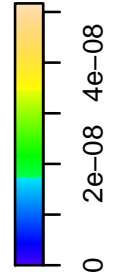

2006-2007

$\left[\begin{array}{l}\infty \\ 0 \\ 0 \\ 0 \\ \infty \\ \infty \\ 0 \\ 1 \\ 0 \\ 0 \\ 0 \\ 0\end{array}\right.$

2009-2010

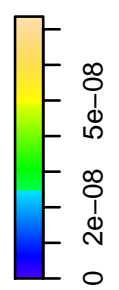

$\left[\begin{array}{l}-\infty \\ 0 \\ 0 \\ 0 \\ \infty \\ -\infty \\ 0 \\ 0 \\ 0 \\ 0 \\ 0 \\ 0\end{array}\right.$ 


\section{(a) CP/PC Sequences}

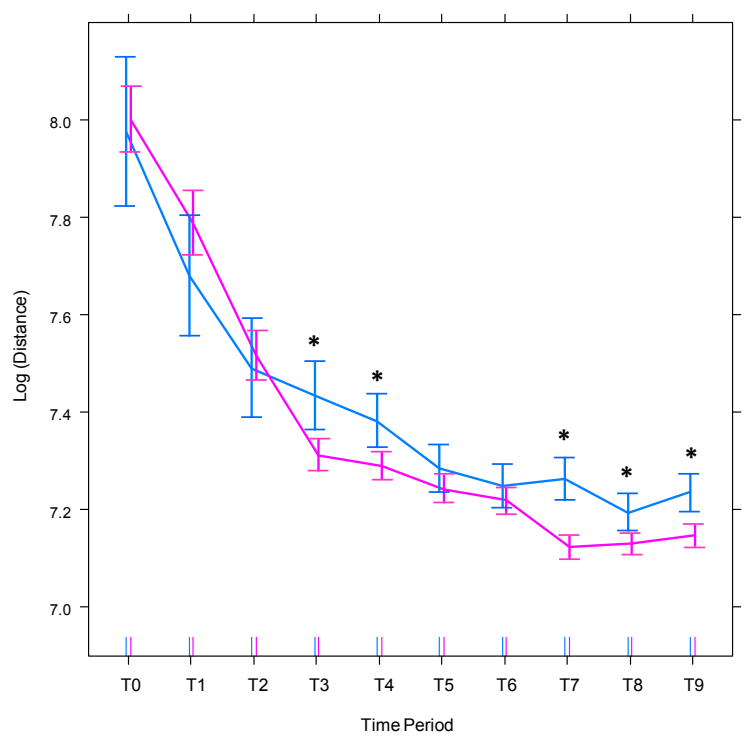

(b) SC Sequences

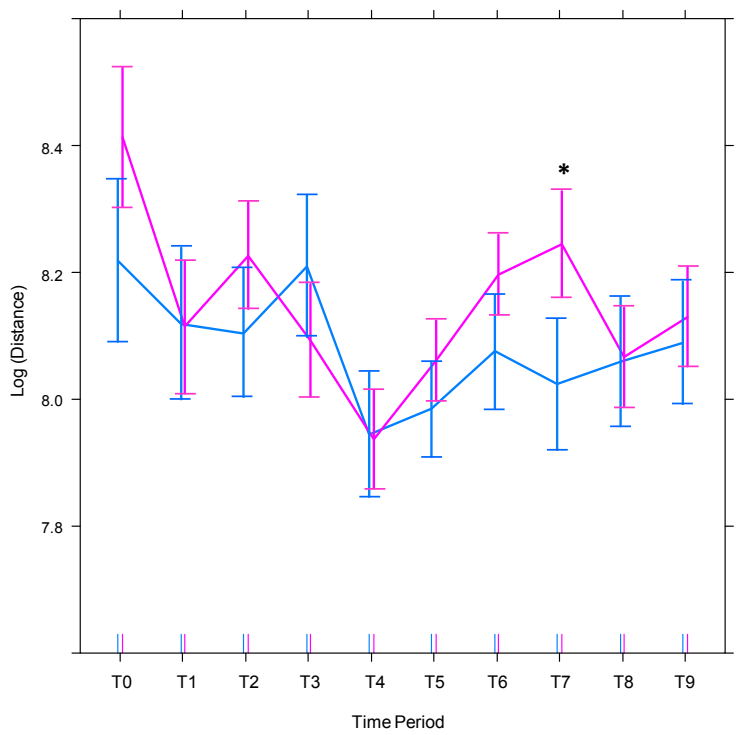

